\title{
PENGEMBANGAN PRODUKTIVITAS BUMDES MELALUI SISTEM INFORMASI E-COMMERCE SEBAGAI SARANA PEMASARAN PRODUK DESA TIMORENG PANUA KABUPATEN SIDENRENG RAPPANG, SULAWESI SELATAN
}

\author{
Aksal Mursalat \& Muhammad Rais Rahmat Razak \\ Fakultas Sains dan Teknologi, Universitas Muhammadiyah Sidenreng Rappang, Sulawesi Selatan \\ Email: aksalmursalat@gmail.com
}

\begin{abstract}
The development of information technology is currently developing very rapidly, especially in terms of mastery of e-commerce information system technology applications. The increasingly rapid development of e-commerce information system technology can be utilized by the community in various fields of life, especially for BUMDES productivity activities in marketing their products. Timoreng Panua Village is one of the villages that has developed BUMDES and has been doing business in the agricultural sector, such as selling fertilizers, seeds, and medicines to combat pests and diseases. However, currently, sales are still carried out manually so that product marketing is still local or limited to residents around the village environment. The purpose of this community service activity is to increase the productivity of the Timoreng Panua BUMDES, especially in terms of marketing its products widely by utilizing e-commerce information system technology through the Agribusiness Store application. The method of implementation carried out is participatory in that in this service the community is proactively involved directly in carrying out activities by involving various stakeholders who are not only from the BUMDES team and group but involve other academics from the Muhammadiyah University of Sidenreng Rappang such as students who are carrying out KKN in the Village. Timoreng Panua in solving priority problems in the partner group totaling 30 participants from BUMDES, village communities, and students. This synergy is carried out to achieve the goals and objectives of the program to be implemented. This service has carried out several activities including counseling on the Agribusiness Store application marketing model, counseling on the explanation of the benefits of the Agribusiness Store application, and the use of the Agribusiness Store application.
\end{abstract}

Keywords: BUMDES, e-commerce, Agribisnis Store

\begin{abstract}
ABSTRAK
Perkembangan teknologi informasi saat ini berkembang sangat pesat, terutama dalam hal penguasaan aplikasi teknologi sistem informasi e-commerce. Perkembangan teknologi sistem informasi ecommerce yang semakin pesat tersebut dapat dimanfaatkan oleh masyarakat dalam berbagai bidang kehidupan khususnya bagi kegiatan produktivitas BUMDES dalam memasarkan hasil produknya. Desa Timoreng Panua merupakan salah satu desa yang mengembangkan BUMDES dan sudah melakukan bisnis di bidang pertanian seperti penjualan pupuk, bibit dan obat-obatan pembasmi hama dan penyakit. Namun, saat ini penjualan yang dilakukan masih secara manual sehingga pemasaran produk masih bersifat lokal atau terbatas pada warga disekitar lingkungan desa saja. Tujuan dari kegiatan pengabdian kepada masyarakat ini untuk meningkatkan produktivitas BUMDES Timoreng Panua khususnya dalam hal memasarkan hasil produk secara luas dengan memanfaatkan teknologi sistem
\end{abstract}


informasi e-commerce melalui aplikasi Agribisnis Store. Metode pelaksanaan yang dilakukan bersifat parsipatori dimana dalam pengabdian ini masyarakat secara proaktif terlibat langsung dalam melaksanakan kegiatan dengan melibatkan berbagai stakeholder yang bukan hanya dari pihak tim dan kelompok BUMDES, tetapi melibatkan pihak akademisi lainnya dari Universitas Muhammadiyah Sidenreng Rappang seperti mahasiswa yang sedang melaksanakan KKN di Desa Timoreng Panua dalam menyelesaikan prioritas permasalahan pada kelompok mitra berjumlah 30 peserta dari BUMDES, masyarakat desa dan mahasiswa. Sinergi ini dilakukan agar tercapai tujuan dan sasaran pada program yang akan dilaksanakan. Pengabdian ini telah melaksanakan beberapa kegiatan antara lain penyuluhan model pemasaran aplikasi Agribisnis Store, penyuluhan pemaparan manfaat aplikasi Agribisnis Store dan penggunaan aplikasi Agribisnis Store.

Kata kunci: BUMDES, e-commerce, Agribisnis Store 


\section{PENDAHULUAN}

Perkembangan teknologi informasi saat ini berkembang sangat pesat, terutama dalam hal penguasaan aplikasi teknologi sistem informasi e-commerce. Perkembangan teknologi sistem informasi e-commerce yang semakin pesat tersebut dapat dimanfaatkan oleh masyarakat dalam berbagai bidang kehidupan khususnya bagi kegiatan produktivitas BUMDES dalam memasarkan hasil produknya. Menurut (Istiqomah et al., 2020) Inovasi merupakan suatu hal yang harus dilakukan oleh perusahaan baik besar maupun kecil untuk tetap dapat bertahan untuk menghadapi perubahan dan perkembangan teknologi.

BUMDES merupakan instrument pendayagunaan ekonomi lokal dengan berbagai ragam jenis potensi (Savitri et al., 2021). Pendayagunaan potensi ini terutama bertujuan untuk peningkatan kesejahteraan ekonomi warga desa melalui pengembangan usaha ekonomi warga. BUMDES atau Badan Usaha Milik Desa merupakan lembaga yang bersifat akomodatif terhadap lembaga peningkatan ekonomi masyarakat pedesaan karena berfungsi sebagai wadah pemusatan kegiatan diantaranya: Pertama, bidang pembiayaan meliputi bidang keuangan yang terdiri atas penghimpunan dan penyaluran dana melalui pimpan pinjam dan pengelolaan resiko. Kedua, bidang non jasa keuangan yang terdiri atas konsultasi manajemen simpan pinjam, pendidikan dan pelatihan, akuntansi dan audit, pengadaan sarana usaha dan audit. Ketiga, pengembangan usaha lainnya seperti pengembangan unit bisnis seperti jasa transportasi, komunikasi dan lainnya (Karim, 2019).

Desa Timoreng Panua merupakan salah satu desa yang sudah menjalankan roda ekonomi kerakyatan yaitu melalui pembentukan BUMDES dan sudah berjalan hingga saat ini. BUMDES Timoreng Panua sudah melakukan bisnis di bidang pertanian seperti penjualan pupuk, bibit dan obatobatan pembasmi hama dan penyakit. Namun, saat ini penjualan yang dilakukan masih secara manual sehingga pemasaran produk masih bersifat lokal atau terbatas pada warga disekitar lingkungan desa saja. Pemanfaatan teknologi informasi khususnya e-commerce dalam memperluas pangsa pasar masih belum dilakukan secara optimal dimana hal ini merupakan kesempatan dan peluang yang seharusnya sudah dapat dilakukan oleh BUMDES Timoreng Panua apalagi untuk akses jaringan di Desa Timoreng Panua sudah memiliki perkembangan teknologi yang semakin pesat. Menurut (Hastriyandi \& Munandar, 2018), dengan adanya sistem penjualan online diharapkan dapat memperluas segmen pemasaran produk BUMDES tidak hanya bersifat lokal, namun meningkat hingga antar desa, kecamatan, kabupaten bahkan ke level nasional dan internasional. Selain itu, (Subagio, 2019) juga mengemukakan dengan melakukan perancangan e-commerce menjadi sektor usaha akan menghasilkan dampak yang banyak karena akses orderan untuk produk BUMDES akan dapat terbuka luas.

Dari permasalahan tersebut inovasi dalam proses pemasaran produk perlu dilakukan agar BUMDES Timoreng Panua dapat meningkatkan produktivitas khususnya dalam hal memasarkan hasil produk secara luas dengan memanfaatkan teknologi sistem informasi e-commerce. Salah satu sistem informasi e-commerce yang ditawarkan dalam pengabdian ini adalah pemanfaatan sistem e-commerce melalui aplikasi "Agribisnis Store" yang bisa di download di Play Store untuk memasarkan hasil produk mitra. Aplikasi "Agribisnis Store" merupakan sebuah aplikasi pemasaran produk untuk memudahkan konsumen dalam memenuhi kebutuhan sehari-hari di bidang pertanian, peternakan dan perikanan, aplikasi ini didirikan oleh Program Studi Agribisnis, Fakultas Sains dan Teknologi, Universitas Muhammadiyah Sidenreng Rappang dalam rangka mewujudkan visi misi yaitu "The Digital Entrepreneurship". 
Selain itu, dalam pemanfaatan aplikasi Agribisnis Store juga tidak hanya fokus kepada produk yang akan dipasarkan, namun juga harus difokuskan pada peningkatan skill sumber daya manusia dalam hal ini adalah BUMDES Timoreng Panua dalam pengembangan produktivitas BUMDES melalui sistem informasi e-commerce sebagai sarana pemasaran.

\section{METODE PELAKSANAAN}

Metode pelaksanaan yang dilakukan adalah metode yang bersifat parsipatori dimana dalam pengabdian ini masyarakat desa dan BUMDES secara proaktif terlibat langsung dalam melaksanakan kegiatan, dengan menawarkan penyuluhan dan pendampingan dalam perluasan area pemasaran dengan sistem e-commerce agribisnis store serta evaluasi untuk melihat efektivitas program dalam sosialisasi dan apakah pelaksanaannya efisien. Pelaksana kegiatan pengabdian ini dilaksanakan di balai Desa Timoreng Panua Kabupaten Sidenreng Rappang, Sulawesi Selatan.

Dalam pelaksanaan kegiatan pengabdian kepada masyarakat ini juga melibatkan berbagai stakeholder yang bukan hanya dari pihak tim dan kelompok BUMDES, tetapi melibatkan pihak akademisi lainnya dari Universitas Muhammadiyah Sidenreng Rappang seperti mahasiswa yang sedang melaksanakan KKN di Desa Timoreng Panua dalam menyelesaikan prioritas permasalahan pada kelompok mitra. Sinergi ini dilakukan agar tercapai tujuan dan sasaran pada program yang akan dilaksanakan.

Tahapan-tahapan dalam pelaksanaan pengabdian masyarakat ini dijelaskan sebagai berikut:

1. Penyuluhan dengan memaparkan model pemasaran sistem informasi aplikasi agribisnis store, dilaksanakan di balai Desa Timoreng Panua Kabupaten Sidenreng Rappang, Sulawesi Selatan. Pelaksana kegiatan pengabdian ini dilaksanakan selama 2 jam dan diikuti oleh peserta BUMDES Timoreng Panua berjumlah 30 peserta dari BUMDES, masyarakat desa dan mahasiswa. Pada kegiatan tersebut tim pelaksana mengadakan penyampaian materi mengenai model pemasaran sistem informasi aplikasi Agribisnis Store guna memberikan wawasan kepada masyarakat dalam mendukung produktivitas usaha BUMDES.

2. Selanjutnya penyuluhan dengan memaparkan manfaat aplikasi agribisnis store, pelaksana kegiatan pengabdian ini dilaksanakan selama 2 jam dan diikuti oleh peserta BUMDES Timoreng Panua berjumlah 30 peserta dari BUMDES, masyarakat desa dan mahasiswa. Pada kegiatan tersebut tim pelaksana pengabdian mengadakan penyuluhan mengenai pentingnya memanfaatkan aplikasi agribisnis store sebagai media pemasaran online dalam mendukung produktivitas usaha BUMDES.

3. Setelah mengetahui model aplikasi Agribisnis Store dan manfaatnya, kemudian tim pelaksana melakukan pendampingan penggunaan teknologi informasi sistem e-commerce melalui aplikasi "Agribisnis Store" dengan memberikan pemahaman kepada mitra untuk memanfaatkan sistem ecommerce dalam perluasan area pemasaran.

Dari tiga tahapan kegiatan pengabdian ini diharapkan dapat memperluas segmen pemasaran produk BUMDES tidak hanya bersifat lokal, namun meningkat hingga antar desa, kecamatan, kabupaten bahkan ke level nasional dan internasional. Untuk metode pelaksanaan yang akan dilakukan untuk mewujudkan pengabdian kepada masyarakat ini tersaji dalam Gambar 1. 


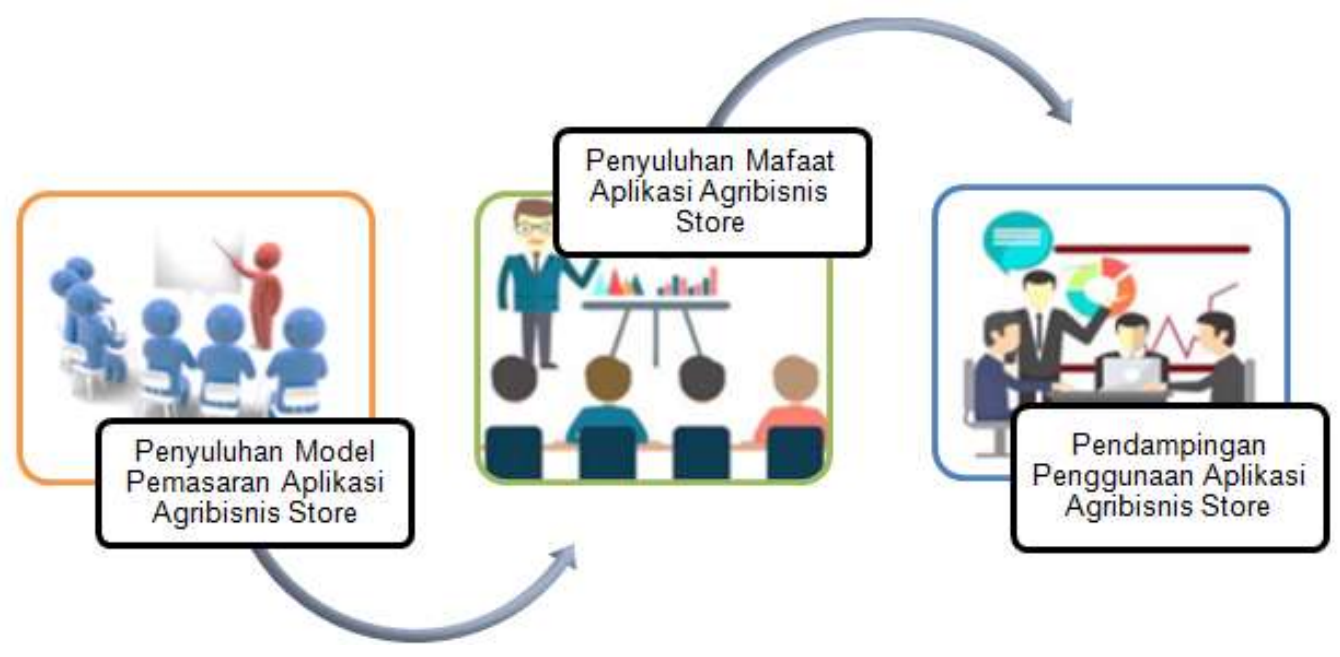

Gambar 1. Tiga tahapan kegiatan pengabdian

\section{HASIL DAN PEMBAHASAN}

Dengan adanya penyuluhan dan pendampingan dalam teknologi sistem informasi e-commerce melalui aplikasi Agribisnis Store dapat memberikan pengetahuan dan menambah ilmu dalam pemasaran berbasis online kepada peserta BUMDES Desa Desa Timoreng Panua Kabupaten Sidenreng Rappang, Sulawesi Selatan. Adapun dokumentasi kegiatan tersebut sebagai berikut:

\section{Penyuluhan Model Pemasaran Aplikasi Agribisnis Store}

Pada kegiatan pengabdian kepada masyarakat ini didahului dengan memberikan materi secara rinci tentang model pemasaran aplikasi agribisnis store. Penyuluhan model pemasaran aplikasi Agribisnis Store ini dilaksanakan di balai Desa Timoreng Panua Kabupaten Sidenreng Rappang, Sulawesi Selatan. Tujuan dari penyuluhan tersebut untuk memberikan pengetahuan bagi peserta BUMDES terkait masalah fitur-fitur yang ada dalam aplikasi tersebut dimulai dari aktivitas transaksi jual-beli hasil produk, dan cara mengupload produk ke aplikasi. Adapun dokumentasi kegiatan ini dapat dilihat pada Gambar 2.

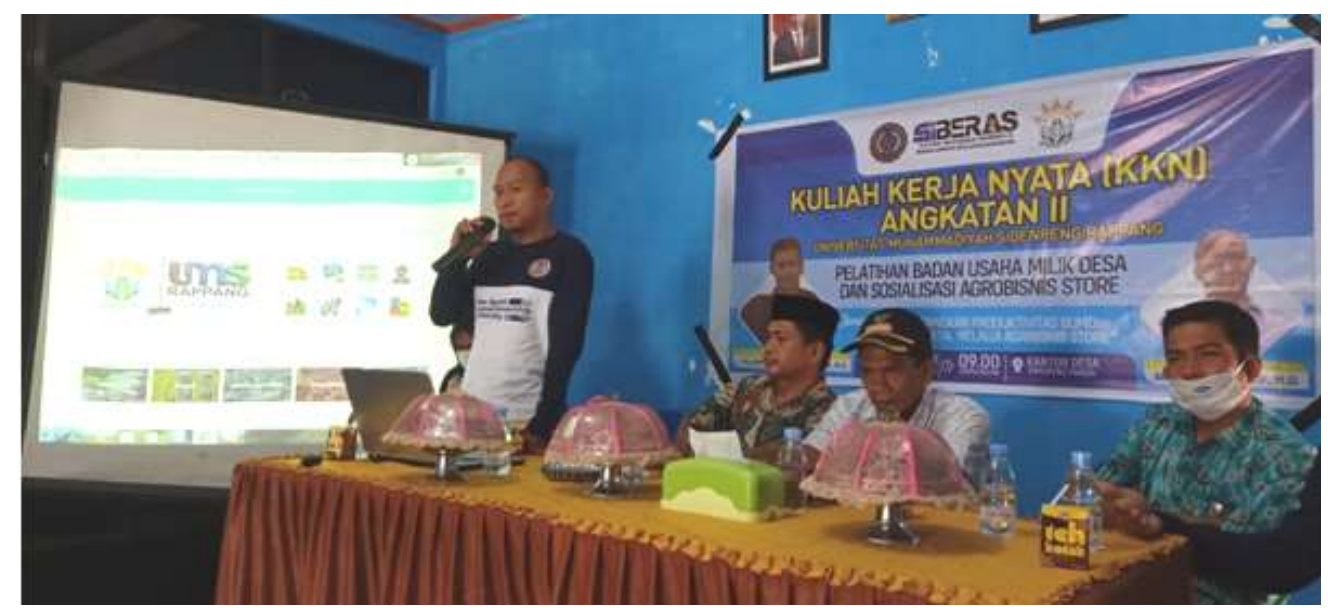

Gambar 2. Dokumentasi penyuluhan model pemasaran aplikasi agribisnis store 


\section{Penyuluhan Pemaparan Manfaat Aplikasi Agribisnis Store}

Pada kegiatan pengabdian masyarakat ini, peserta BUMDES diberikan pemaparan materi tentang perkembangan teknologi sistem informasi e-commerce melalui aplikasi Agribisnis Store. Dalam pemaparan materi tersebut dijelaskan beberapa manfaat dalam melakukan pemasaran melalui aplikasi Agribisnis Store diantaranya, dengan memasarkan hasil produk di aplikasi Agribisnis Store dapat mempermudah komunikasi antara penjual dan pembeli, mempermudah pemasaran dan promosi barang serta memperluas jangkauan konsumen dengan pasar yang luas. Adapun dokumentasi kegiatan pengabdian kepada masyarakat tersebut dapat dilihat pada Gambar 3.

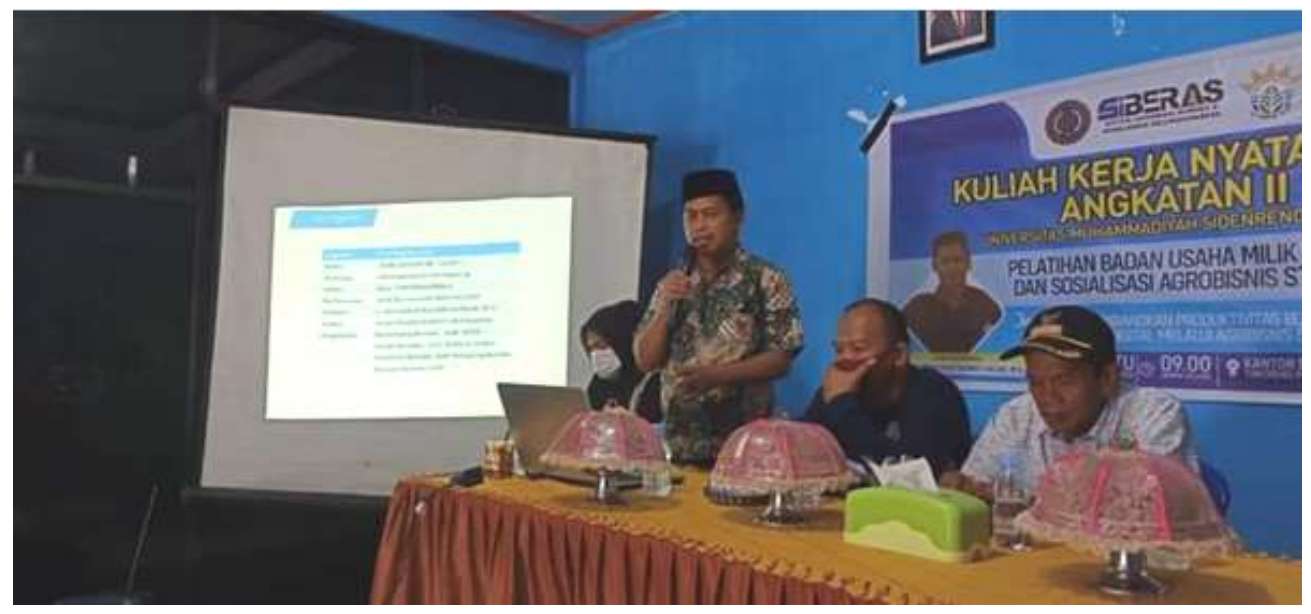

Gambar 3. Dokumentasi penyuluhan pemaparan manfaat aplikasi agribisnis store

\section{SIMPULAN}

Adanya penyuluhan dan pendampingan dalam penerapan sistem informasi e-commerce melalui aplikasi Agribisnis Store pada produk BUMDES di Desa Timoreng Panua dapat memberikan manfaat yang sangat besar untuk meningkatkan produktivitas khususnya dalam hal memasarkan hasil pemasaran produk BUMDES. Produk yang dipasarkan lebih dikenal masyarakat tidak hanya pada masyarakat disekitar lingkungan desa saja namun bisa sampai dikenal secara luas. Dari seluruh kegiatan pengabdian yang dilakukan di Balai Desa Timoreng Panua, dapat disimpulkan bahwa penerimaan masyarakat, baik pengurus desa, maupun pihak BUMDES adalah sangat baik sekali. Masyarakat mengikuti dengan baik tahap penyuluhan dan pendampingan yang diadakan serta melakukan uji coba pada aplikasi yang diseminasikan.

Untuk mencapai hasil yang maksimal dalam pengembangan produktivitas BUMDES melalui sistem informasi e-commerce sebagai sarana pemasaran produk Desa Timoreng Panua, selanjutnya akan dilakukan monitoring terhadap perkembangan hasil pemasaran usaha produk BUMDES Timoreng Panua.

\section{UCAPAN TERIMAKASIH}

Ucapan terimakasih disampaikan kepada LP3M Universitas Muhammadiyah Sidenreng Rappang serta Kepala Desa Timoreng Panua yang telah mendukung pada kegiatan pengabdian kepada masyarakat ini. Kami juga mengucapkan terimaksih kepada para peserta BUMDES Timoreng Panua yang telah berpartisipasi dalam melaksanakan kegiatan serta pihak terkait yang telah membantu dalam proses kegiatan pengabdian kepada masyarakat ini. Terimakasih juga secara khusus diberikan kepada pengeditan naskah secara cermat sehingga artikel ini layak diterbitkan. 


\section{REFERENSI}

Hastriyandi, H. \& Munandar. (2018). Penerapan Sistem Pemasaran Berbasis Online Pada Produk Badan Usaha Milik Desa (Bumdes) "Usaha Bersama" Desa Sebayan Kabupaten Sambas. Amaliah: Jurnal Pengabdian Kepada Masyarakat, 2(2), 189-195. https://doi.org/10.32696/ ajpkm.v2i2.201.

Istiqomah, S., Fajaryanti, Y., \& Dewi, A. S. (2020). Peningkatan Kinerja Bisnis Melalui Strategi Pemasaran Berbasis Online Pada Ukm Produk Camilan Tradisional. Diseminasi: Jurnal Pengabdian Kepada Masyarakat, 2(1), 5-18. https://doi.org/10.33830/diseminasiabdimas. v2i1.750.

Karim, A. (2019). Peningkatan Ekonomi Desa Melalui Badan Usaha Milik Desa (BUMDes). In CV. Nas Media Pustaka, Makassar. https://www.academia.edu/download/62440051/EBOOK-BUMDes 20200322-77446-186t2rg.pdf.

Savitri, D. A. M., Nugroho, P. S., \& Kurniasari, D. (2021). Peningkatan Kapasitas Teknis Desa Pengembangan Ekonomi Lokal Melalui Bumdes "Gemar" Desa Parakan, Kendal. BUDIMAS: Jurnal Pengabdian Masyarakat, 3(1), 40-47. https://doi.org/10.29040/budimas.v3i1.1633.

Subagio, S. (2019). Perancangan E-commerce Hasil Produk BUMDES Desa N8 Labuhanbatu Dalam Meningkatkan Nilai Ekonomis bagi Ibu-ibu Rumah Tangga Desa N8. Jurnal Informasi Komputer Logika, 1(3). http://ojs.logika.ac.id/index.php/jik//article/view/44/49. 